\section{SICALLPOX-OLD AND NEW."}

\section{L. REEBE, M.1).}

ST. (LOUn, MIXX.

The above title evidences our belief that the epidemic which has been prevailing throughout the United States and our new possessions for the past two years, is not identical with the old-fashioned smallpox of twenty vears ago. I have been identified with two epidemicstwenty years apart-and though they were evidently both species of smallpox, thev were nevertheless very dissimilar in many characteristics. Without exception, the descriptive adjectives applied to our later epidemic, whether through the reports in our daily papers, or in the more authoritative reports in the medical journals, all contain such terms is "mild," "modified." "light type," etc., and many medical men, even up to this day, deny that our present disease is, in fact, smallpox.

It is safe to assert that more of the recent cases have been diagnosed (hicken-pox than smallpox, and I am free to confess that in the first two cases that I sawa vear having clapsed between the cases- $\mathrm{I}$ was of the opinion that they were not true smallpox. When we passed through the epidemic twenty years ago there was never any difficulty in diagnosing the disease, though I had never previous to that time seen a case. The attacks then were so typical of the disease, as described in our text-books, that there could be no mistaking it. This season when we went, confident of our ability to differentiate this disease from all others, and were compelled very meekly and modestly to say: "Well, ] do not know. I am in doubt as to whether it is a very severe case of chicken-pox or a very mild case of smallpox," and had to send to our state boards of health for a recision, rou can readily imagine our embarrassment.

I want to show two or three peculiarities of our recent epidemic. The first case was the wife of a man who was markedly pitted from an attack of smallpox occurring several years previously. This man contracted the new disease from his wife; a sister and little child. neither of whom had been vaceinated and who were in the same rooms with my patient throughout the attack, were not affected by it. In fact, the question as to whether immunity or mitigation of the severity of our recent cases was conferred by vaccination was very much of a question. It is not at all a settled fact that the patients previously vaccinated showed a modified form in any manner. We had several patients that had never been vaccinated, but we are unable to say that the diseave was more severe in their cases than in those who had been vaccinated. Of course, here would come in the question of an inherited immunity, vaccination having been very thorough of late years on the part of the parents of most of the patients. This fact has been advanced as a possible cause of the unquestionable mildness that the present epidemic has assumed. Whether through the thorough vaccination of generations of ancestors partial immunity can be established admits of some doubt: and ret it is a very ingenious explanation of an otherwise unexplainable fact.

I recentlo saw a family of thirteen that had passed through the disease, all having been afflicted; the parents only had been vaccinated, and ret I was unable to see that the vaccination had in the least mitigated the severity of the disease. The parents were pitted as much as the eleven children, and they claimed they had been

* Read in Symposium on Smallpox. in the Section on I'ractice of Medicine, at the Fifty-second Annual Meting of the American Mrdical Association, held at St. Paul. Mimm. June 4-7, 1901 just as sick. This family had been infected by a child with what a local physician called chicken-pox.

Notwithstanding these stubborn facts, we do not desire to be classed in the ranks of the disbelievers in the efficacy of vaccination. In fact it is our intention, when opportunity offers, to act on the suggestion of Dr. Stern, of New York. He presented, in a paper to the Manhattan Clinical Society, in April, 1901, a report of ten or twelve cases of uricacidemia, gouty, rheumatic and neuralgic diseases that had been materially improved in condition and entirely relieved of pain by vaccination.

\section{SANITARY FEATURES OF SMALLPOX.* \\ LOULS LEROY. M.D. \\ NASIVILLE. TEXX.}

Smallpox is a disease which possibly above all others should be dealt with by health authorities. The question as to whether it is best handled by local or state boards of health will depend, of course, largely upon the organization and efficiency of the former. In well-organized communities, such as is usually found in the larger cities, it is wisest to deal with the cases at the place of development rather than to attempt any transportation. In some of the more scattered cases, which will come under the jurisdiction of the county boards of health, oftentimes the intervention and usually more rigid management of the state authorities is unquestionably required. This oceasionally will meet witl come local opposition by individuals who may regard it as an act usurping the local rights, but experience had shown that a great many personal interests are constantly at stake and these often tend greatly to hamper the thoroughness of the physician in charge. Upon the outbreak of one or more cases in a locality, in competent physician should be placed in charge and be given as nearly as possible absolute power. By so doing, all unnecessary and dangerous delay, which results from debates and diversities of opinion and interests, will be avoided and a better concentration of action be obtained. The physician in charge should be in communication with the Board of Health, preferably by means of a telephone from the infected district. In this way he will avoid much unnecessary traveling about. which, even though all precautions are observed, tends to unnecessarily alarm the community.

The strongest possible police co-operation should be obtained, in order to prevent the numerous acts, which are almost certain to occur, in a disregard to the orders, and vigorous legal prosecution should be instituted at once upon the least wilful infringement of quarantine regulations.

This is necessary. because if the slightest laxness is permitted in the beginning, it will be almost an impossibility to again establish the necessary discipline. Great care should be exercised also, in the granting of any privileges, which might be construed as special dispensations. Again, in all epidemics there will always be found floating about all kinds of reports and rumors, which tend to keep the community in an unnecessary state of excitement and have an injurious effect upon all commercial enterprises of the locality. In order to aroid this as much as possible, we have found it a satisfactory plan to make a daily official report to the newspapers, stating the exact condition of affairs as

* Read in Sympesium on Smallpox. in the Section ou lractice of Aledicine, at the Fifty-second Annial Meeting of the Amerimn Iradical Association. held at St. I'anl, Mlinn. June $4-\tau$. 1901 . 
nearly as possible, without exaggerating or belittling any feature of the situation.

'The question of treating the cases in their own homes is an ever-present one, and in many cases must be considered seriously. In the finer houses this can frequently be done with some degree of satisfaction. There will, of course, be a larger amount of furniture, hangings, carpets, etc., to disinfect subsequently: and there are liable to be more people exposed to infection; but, on the other hand, the people are more apt to follow directions intelligently and not to try wilfully to deceive the authorities. A special room is more easily devoted to the purpose and special nurses can more readily be obtained. In the poorer class of houses it is often difficult to obtain complete isolation or care and frequently less intelligent nursing will be obtained. In the case of tenement houses, the treatment at the home should not for a moment be considered. As a general rule, it may be stated that the treatment of smallpox in a private house is at best but a makeshift.

As soon as the authorities are informed of a suspicious case, it should be isolated completely for a few days, until further development of the symptoms render diagnosis certain. During this time no one but the physician in charge and the nurse should, under any circumstances, be allowed to enter the room, for, although the chances of infection at this stage are comparatively slight, still there is always a possibility of transmitting the disease, and the additional risk of permitting visitors in the sick-room is not justified. All articles which the patient uses, such as knives. forks, dishes, etc., should be well boiled before being used by anyone else.

If, in the course of a day or so, the characteristic: symptoms and eruptions appear, making the diagnosis certain, the patient should be removed immediately to a hospital devoted to the care of such cases. All persons who have been exposed to the patient should be immediately vaccinated and kept under surveillance for a period of fifteen days from the last possible chance of their having been infected. The room and all its furniture should be disinfected, as mentioned later. No pains should be spared to determine the source from which the disease was contracted, as, by so doing, we may frequently be able to find a large number of persons who may have been subsequently exposed to the same source of danger, and who, therefore, should also be vaccinated and watched by the health authorities.

In some places, for financial reasons, it has been the custom to allow all persons known to have been exposed, to go about absolutely unhindered during a period of incubation pending the development of further symptoms. First obtaining. however, a promise from such persons to report to the authorities in case any symptom of the disease manifests itself. We can not condemn this method too severely, for it can not be applied to all cases, for the reason that, unfortunately, many people will use the time thus gained to make good their escape from the community, or, if they develop a mild case, will occasionally fail to report it until the disease is well developed and many more people have been exposed. It is true that if proper precautions are taken to disinfect the clothes and persons of the ones suspected. comparatively little danger will be produced by this system, providing that we have the intelligent and conscientious assistance of the persons exposed. As this is not possible, however, we can not make special laws or regulations for certain individuals during an epidemic without creating too great an opposition from public sentiment, particularly from those quarters from which we naturally expect and invariably find the greatest opposition to any sanitary regulations.

In large cities it is generally an easy matter to obtain a large building for the organization of a pest-house, and this can usually be done very satisfactorily. In the less densely populated locality, however, tents offer the most convenient and efficient means of isolation. They are cheap, easily procured, can be erected immediately, and, from the standpoint of the patient, are probably more wholesome than buildings. If possible, two large tents and two or three smaller ones should be obtained. The two large ones can be utilized respectively for male and female patients. One of the smaller ones as a kitchen and commissary department, another for the physician in charge and his assistants, in which may also be kept the medical stores and, if possible, above all things, a telephone. The tents should be floored with matched boards or sawdust to a depth of one or two inches, should be provided with good flies, and be well ditched. If possible, they should be upon high, sandy ground and not within 300 yards of other residences. If the weather be cold, they can be easily heated by small stoves placed near the center of the tent, and we have found that the small wood-burning stoves give better satisfaction and can be tended with less trouble than the larger coal stoves. Cots can be obtained cheaply, and straw mattresses easily improvised. Two sets of bedclothes will usually be found sufficient and should be boiled and changed alternately every two days. The cooking can be done in one tent and brought and deposited on a table just outside of the hospital tent, from which place the nurses can carry it to the patients. All unused remnants from the plates should be thrown into the fire, and the dishes, etc., dropped into boiling water by the nurses before being handled by the cook. In this disease, as in many others, much depends upon the nursing, and it is a poor economy which seeks to save unduly in this respect. Night and day nurses are indispensable where there are many or severe cases.

Where there are quite a number of cases to handle a horse and wagon is almost a requisite. Arrange ments should be made with the merchants of a town to furnish all necessary articles. These can be ordered by telephone and delivered to the edge of the quarantined line, where they are called for by a guard or a wagon and carried to headquarters. In this way, there is no exposure of the deliverer in handling supplies, and no time is lost in receiving them. Strict account of all articles ordered should be kept by the physician in charge and handed in with his report.

As soon as the patient leaves his house, whether recov. ered or removed to a hospital, the premises and all articles, which have in any way come in contact with him, should be disinfected. Everything possible should be burned. The carpets may be removed and disinfected, where possible, by being ripped into the original strips and placed in the steam autoclaves, or, where these are not available, may be thoroughly sprinkled with formalin. For articles of clothing or finer articles, such as draperies or curtains, a tight. wooden box may be improvised, into which they may be placed and liberally sprinkled with formalin. Other articles, as sheets and pillow-slips, should be boiled and the contents of the pillows and mattresses, in case they can not be burned, should be exposed to the air of the room during subsequent fumigation. 
All wooden articles, the floor, walls and ceilings should be thoroughly sponged with a 1 to 1000 solution of bichlorid of mercury. In the houses which are tightly built, formalin may give good results, but in our work in Tennessee, we have not been satisfied with any of the forms of formaldehyde generators which we have tried. This possibly can be accounted for by the fact that most of the houses in which the disease has been present havo been of the poorer class of negro hovels. It is impossible to render these even approximately air-tight. In these cases, we have found that sulphur bas given the best results, and have used relatively large quantities of it, burning several piles of ten pounds each in a room at the sane time, in order to liberate as large a volume as possible of sulphur dioxid at a time. care being taken to make the room as tight as possible. Near the hospital tents, pits are dug and filled with quicklime, for receiving all discharges and waste material, and the discharges are mixed with an equal volume of a saturated solution of ordinary chlorid of lime and allowed to stand a half hour before being thrown out.

When a patient is ready to leave the hospital, he is made to thoroughly bathe himself and shampoo his hair. He resumes his clothing, which has been sterilized thoroughly. A large dry-goods box may be rendered airtight by coating the inside with a mixture of equal parts of resin and paraffin, which is melted and poured into all cracks and crevices.

The clothes may be placed in this and sufficient formalin added to moisten them, when the lid will be closed, and they are allowed to remain for twenty-four hours. This has always proved satisfactory in our work and does the clothes no injury.

When the epidemic is terminated all the cots and bedding, together with the tent-floors, should be burned, and the tents themselves thoroughly saturated with a 1 to 1000 solution of bichlorid of mercury. The ground under and around the tents can be sprinkled with a saturated solution of chlorid of lime. When the tents have dried and been allowed to air for a day or two they should be taken down and stored away for future use, without fear of carrying any infection; the ropes must be burned.

At present there are practically two methods of vaccination in use, that with a dry point, and with the glycerinated lymph. The latter is unquestionably the best, but, unfortunately, has its drawbacks. Elgin has shown that in the dry points the pus-producing bacteria will live long after the virus of vaccinia has lost its potency, so that we not infrequently will find, as a result of vaccination with old points, septic arms, which, while they may be extremely sore, have absolutely no protective value. On the other hand, the glycerinated lymph in a short while becomes comparatively sterile as far as pyogenic organisms are concerned, but the virus loses none of its potency.

One of the main objections to the glycerinated lymph is, that it requires a long time to dry, and, that being somewhat viscid, it tends to cause foreign substances to adhere while it is exposed to the air. In this way we have a constant liability to infection at the time of inoculation. In order to obviate this I have introduced into Tennessee this year on a large scale, the hypodermic needle as a means of introducing the vaccine beneath the skin. I have not had an opportunity to search the literature of the subject to see whether this method has been used by other workers in the field. The writer first employed this method in Philadelphia in 1895, at which time he used an aqueous solution from the dry points. Later, however, when the glycerinated lymph came more into voguc, that was substituted for the aqueous solution, with the result of an almost perfect method of raccination.

In order to use this method a solid-piston hypodermic needle is used, and, if a large number of vaccinations are to be performed, the barrel of the needle may be filled with the glycerinated lymph, which may be obtained in large tubes, containing sufficient of the lymph for fifty cases. A short and rather large caliber needle is most satisfactory. The skin is cleansed in the usual way and a drop of the lymph injected, with the concave surface of the needle downward. In this way the drop of lymph is forced between the epithelial cells and diffuses in exactly the locality desired. As a rule, a single minim is sufficient, although we have injected upward of ten minims without deleterious results. Another advantage of this method is, that in cases of compulsory vaccination the virus can not be removed by washing, as is frequently done when the ordinary point is used. Again, in the South, where we have a large colored population, there exists among them a universal superstition which leads them to expectorate into the vaccination, with the almost constant result of a septic sore. This not only is undesirable for the patient, but is also a menace to the safety of the community, because this septic sore is not protected, while believed to be so, and the result is a feeling of false security. It also offers a pseudo-argument for a class of anti-vaccinationists and individuals, who, from one motive or another, are but too glad to deny the existence of the disease, or who, through a process of vicious reasoning, try to assert that any disease which present itself upon a vaccinated individual can not be rininla. Then again, there is an absolute freedom from danger days after. If it does not "take," there will be no further inconvenience whatever, as no immediate dressing is necessary. The process is entirely painless, a point which will not be lost sight of in the case of it child or nervous patient, to whom the repeated scratching necessary in scarifying is generally extremely irritating. The great rapidity with which the process can be carried out is of great value where large numbers must be immunized in a short time.

A materially larger percentage of successful result. will be obtained in this way than by simple scarifying. and we have repeatedly had cases develop a typical, clean vaccination, which had proved refractory to several previous vaccinations with points.

We also believe that by repeated vaccinations by this method, and by slightly increasing the amount injected, that a higher grade of immunity can be produeed than where the point is used. The writer has immunized limself in this way and performed some dozens of a utopsies with bare hands upon smallpox cadavers, with. out any further inconvenience than a slight sentir infection of two fingers on the left hand. It can not bo said that the same immunity might not have been produced by vaccination with the point, but reasoning from the analogy of other immunizations, we should be able, by using and getting absorption of a larger amount of the virus, to develop a higher resistance to the disease.

Where it is possible to handle the work in any other way, extensive quarantines should not be executed, and where they are, it is most usually an evidence of ineffriency of the local boards, which should have charge of the outbreak. When, however, a quarantine is decided 
upon as a necessary step, it should consist of at least two separate areas. One to be used by the sick, the other as a camp of detention, in which suspected or exposed cases may sojourn until the presence or absence of the disease can be determined, then their case can be dealt with accordingly.

In the case of large establishments or mines, it often becomes a very serious question in the minds of the authorities as to the wisest course to pursue. If the case has been recognized early and but few of the employes have been exposed, it is manifestly unjust to require the closing of the entire establishment. But, on the other hand, if precautions are not taken there may result a very serious outbreak of the disease. In these cases, if the co-operation of the managers can be obtained, a universal compulsory vaccination, and directions that foremen keep close watch upon all employes for any evidences of sickness, and that any employe who may not be well be returned home until entirely recovered, will generally prevent danger of a severe outbreak. But if, as unfortunately is sometimes the case, the management evinces an inclination to deceive the authorities, the whole institution should be uncompromisingly closed for a period of fifteen days. By that time any which were infected at the time will have developed.

In a mine, where the working population is of a floating class, a compulsory vaccination, with the issuing of individual certificates bearing the name and description of the holder, should be instituted and the foremen instructed to see that each man under his direction be provided with such certificate before being allowed to work. This will usually be sufficient, but we have found in some cases that it was fuicher necessary to send inspectors occasionally through the plant to see that each individual had with him his certificate.

Again, as unscrupulous physicians have been encountered who have issued spurious certificates of raccination over their own signatures, or who have wilfully made sterile scarifications to simulate vaccination, it may at times be wisest for the physician in charge to recognize or accept absolutely no certificate but his own or that of his assistants, thereby avoiding all personal discrimination, and, by revaccinating all doubtful cases. be positive of having discharged his duty to the best of his ability.

\section{THE DIAGNOSIS OF MILD AND IRREGLTAR SMALLPOX AS FOUND TN THE PRESENT OUTBREA ${ }^{\circ} K$ IN THE UNITED STATES.*}

\section{HEMAN SPALDING, M.I).}

CHIEF MEDICAI INSPECTOR, DEPARTAMENT OF HEATH. CHICAGO.

In this paper I will mention and describe only the cases of smallpox which have come under my personal observation during the past two years. Previous to 1899 Chicago had been practically free from smallpox for more than a year, having had but one case in 1898 . From March 9, 1899, to the present time-about 2 ? months-310 cases of smallpox have been found in Chicago. Sixty-four of these in various stages of the disease were imported into the city from nineteen of the surrounding states. The cases came from as far east as New York and as far west as California. In the

* Read in Symposium on Smallpox, in the Section on I'ractice of Medicine, at the Fifty-second Annual Mceting of the American Medical Association, held at St. Faul, Minn., June 4-7, 1901. meantime, I visited three of the neighboring states where the diagnosis of this disease, variously called impetigo contagiosa, giant chicken-pox, Cuban itch, or some other indefinite name, was in dispute. With this opportunity of observing cases imported from such widespread and various sources, I think it is fair to assume that the disease we call smallpox in Chicago is the same discase which has been the subject of controversy in all parts of the United States.

On February 15, 1899, a colored man and wife, named Edmonson, arrired in Chicago from Cincinnat, sick with smallpox in a mild form. A physician wis called, who promptly made a diagnosis of chicken-pox and treated them for that disease. Sereral cases of smallpox resulted from this mistake in diagnosis. This was the beginning of periodic importations of smallpox to Chicago from neighboring cities and states, which have continued up to the present time.

From the date of the discovery of this first case, Narch 9, 1899, to August 16;1900-17 months-we had 72 cases of smallpox, 25 of which were direct importations. From this last date, August 16, 1900, to November 30. a period of three and a half months, we were entirely free from the disease. 'This marked the end of the first influx of the much-discussed disease. On November 30, 1900, Charles L., in the pustular stage of smallpox, came to Chicago from Ashland, Wis., over the C. \& N.-W. Ry. He walked into the City Hall, mingled with the crowds in the halls and elevators, visited varions departments of public service and finally came to the Department of Health. where he was safely cared for. The day before this man arrived the Healti Department had issued a warning to the public to vaccinate and revaccinate, as smallpox was to be found in all of the surrounding states. This case from Ashland was the beginning of a succession of importations and exposures which during the last six months have given us 238 cases of smallpox, 39 of which came from without the city. Thesc two outbreaks of smallpox, with but three months intervening, gave us an opportunity to study 310 cases in the Chicago Isolation Hospital. Numerous forms of the disease were found. The typical case was always present, but the greatest number were deviations from this trpe. These deviations represented such a variety of forms that almost every case had something peculiar to itself, but the followin? classifications which I have made will aid in giving an intelligent description of the various forms:

1 Hemorrhagic case, resulting in death.

13 Confluent, with 3 deaths.

$2+$ Semi-confluent, with 2 deaths.

04 Severe discrete cases, with no deaths.

$1 \%$ ) Mild discrete cases, with no deaths.

39 Modified form-cases in which there was evidenco of a more or less successful vaccination, with no deaths.

In this outbreak I have seen no cases of smallpox without eruption. I an satisfied this form-variola sine eruptione-exists. In the epidemic in Chicago of 1894-5, I carefully observed and studied thirtv cases this form. 'The evidence was conclusive to me that such cases exist. All the cases I saw of this form were in adults with old vaccination marks.

I have seen no cases with the initial rash in this present outbreak, though one man stated he had a rash over the body the second day of the discase, which disappeared the following day. 